\title{
Temporal Dynamics of action perception: Differences on ERP evoked by Object- Related and Non-Object-Related Actions
}

\author{
Yannick Wamain $^{1,2}$, Ewa Pluciennicka ${ }^{1,2}$, Solène Kalénine $e^{1,3,4}$ \\ ${ }^{1}$ Université Lille Nord de France, F-59000 Lille, France \\ ${ }^{2}$ UDL3, URECA, F-59653 Villeneuve d'Ascq Cedex, France \\ ${ }^{3}$ UDL3, IRHIS, F-59653 Villeneuve d'Ascq Cedex, France \\ ${ }^{4}$ CNRS, URM8529, F-59653 Villeneuve d'Ascq Cedex, France.
}

\begin{abstract}
:
While neuropsychological dissociations suggest that distinct processes are involved in execution or perception of transitive (object-related) and intransitive (non-objectrelated) actions, the few neuroimaging studies that directly contrasted the brain activations underlying transitive and intransitive gesture perception failed to find substantial differences between the two action types. However, the distinction could be visible on brain activity timing within the fronto-parietal network. In this study, we used Event-Related Potential (ERP) method to assess the temporal dynamics of object-related and non-object-related action processing. Although both meaningful, only object-related actions involve object motor features. Accordingly, perception of the two action types would show distinct neural correlates. Participants were presented with four movie types (ORA, Object-Related Action, NORA: Non-ObjectRelated Action and 2 control movies) and were instructed to perform tasks that required explicit or implicit action recognition (specific action recognition or color change detection). Movies were presented as Point-Light Display (PLD) and thus provided only information about gesture kinematics regardless of action type. ERP were computed during movie visual perception and analyzed as a function of movie type and task. The main result revealed a difference between ORA and NORA on the amplitude of the P3a component in the fronto-parietal region. The difference observed around $250 \mathrm{~ms}$ after movie onset do not likely origin from variation in low-level visual features or attention resource allocation. Instead, we suggest that it reflects incidental recruitment of object attributes during object-related action perception. The exact nature of these attributes is discussed.
\end{abstract}

KeYwords: EEG; Action perception; Object Knowledge; Point Light Display; Transitive and Intransitive Action 


\section{INTRODUCTION}

Several influential models of gesture production suggest that distinct cognitive mechanisms are devoted to the execution of different gesture types. Based on the observation of apraxic patients, such models typically propose two distinct routes for action, a semantic route and a non-semantic route (Buxbaum, 2001; Cubelli, Marchetti, Boscolo, \& Della Sala, 2000; Gonzalez Rothi, Ochipa, \& Heilman, 1991). The two routes would be differentially involved in the production of meaningless, transitive, and intransitive gestures. While imitation of meaningless gestures can only rely on the direct, non-semantic route for action, execution of both transitive (i.e. object-related) and intransitive (i.e. non-object-related) gestures can tap onto the semantic or non-semantic route. In other words, executing intransitive actions as well as pantomimes of object use may involve semantic representations. However, it is still unclear whether transitive and intransitive gestures rely on distinct cognitive and neural mechanisms.

Distinction between production of transitive and intransitive gestures has been first documented in the neuropsychological literature. Patients with strongly impaired transitive gesture production and relatively preserved intransitive gesture execution have been reported many times following left hemisphere lesions (Dumont, Ska, \& Schiavetto, 1999; Foundas et al., 1995; Haaland, Harrington, \& Knight, 2000; Rapcsak, Ochipa, Beeson, \& Rubens, 1993; Roy, Square-Storer, Hogg, \& Adams, 1991). Based on these observations, it has been suggested that transitive and intransitive gesture execution rely on distinct cognitive networks. However, transitive gestures could be simply more difficult to perform than intransitive gestures. Several behavioral results are consistent with this alternative interpretation. Using more 
refined measures of gesture production accuracy, Carmo \& Rumiati (2009) revealed that healthy participants imitated intransitive gestures better than transitive gestures (see also Mozaz, Rothi, Anderson, Crucian, \& Heilman, 2002, for similar results). Thus, differences in gesture execution complexity could account for the greater deficits in transitive gesture production frequently reported in apraxic patients.

In this context, neuroimaging studies have tried to identify the neural substrates that would be specific to transitive action planning and execution (Bohlhalter et al., 2009; Culham, 2004; Fridman et al., 2006; Johnson-frey, Newmannorlund, \& Grafton, 2005; Króliczak \& Frey, 2009). Although both gesture types recruit a left-lateralized fronto-parietal network (but see Bohlhalter et al., 2008 for a right hemispheric dominance for intransitive gestures), some areas of this network have been shown to be more active during preparation and/or execution of transitive compared to intransitive actions (Buxbaum, Kyle, Grossman, \& Coslett, 2007; Culham et al., 2003; Fridman et al., 2006; Haaland, Harrington, \& Knight, 2000; Króliczak \& Frey, 2009; Wheaton \& Hallett, 2007). As suggested by Króliczak and collaborators in their interpretation (Króliczak \& Frey, 2009), the differences observed may also depend on movement complexity since sensory-motor cortex activity and movement complexity are closely linked (Gut et al., 2007). Thus, findings from neuroimaging studies corroborate neuropsychological observations and suggest that the stronger fronto-parietal involvement observed during production of transitive compared to intransitive gestures is probably caused by greater difficulty of transitive gesture execution.

Recently, the pattern of apraxic deficits presented by an autistic child refuelled the debate on the transitive-intransitive gesture distinction. Ham, Bartolo, Corley, Swanson \& Rajendran (2010) reported the case of JK, who exhibited a 
selective impairment in producing intransitive gestures with normal scores in transitive gesture production. The existence of a double dissociation between the deficits presented by this child and the impairments of apraxic patients showing the opposite pattern suggests that the difference between transitive and intransitive gesture execution goes beyond difficulty.

In the present study, we aimed at investigating the neural correlates of transitive (object-related) and intransitive (non-object-related) action processing in perceptual tasks. We used perceptual tasks for two reasons. First, neuroimaging studies using production tasks lack appropriate baseline conditions for transitive and intransitive gesture comparison (Króliczak \& Frey, 2009). Since gesture complexity is not matched between action types, it is tricky to draw conclusions about the specific neural substrates of object-related and non-object-related actions from production data. This limit is less difficult to overcome in perception. Accordingly, we designed perceptual control stimuli that were equivalent to the perceived transitive and intransitive actions in term of visual complexity. Second, in order to keep transitive and intransitive gestures equivalent, objects could not be presented. Moreover, we wanted to avoid pantomime tasks, since there is evidence of partially distinct neural circuits for real and pantomimed gesture execution (Króliczak, Cavina-Pratesi, Goodman, \& Culham, 2007; Senkfor, 2008). Thus, the use of a perceptual paradigm allowed the assessment of object-related actions without involving objects or pantomimes.

On the one hand, the two routes of action models (Buxbaum, 2001; Cubelli et al., 2000; Gonzalez Rothi et al., 1991) suggest that both object-related and nonobject-related actions could involve some kind of semantic representations. On the other hand, it has been argued that in many situations, object-related actions require 
accessing both action and object representations (Buxbaum, 2001; Frey, 2007). This characteristic can obviously not apply to non-object-related actions, suggesting that additional semantic processes are involved in visual perception of objet-related actions. Thus, perception of object-related actions, but not non-object-related actions, would involve the recruitment of object knowledge and in particular object motor features (Buxbaum et al., 2007; Chao \& Martin, 2000; Martin, 2007). Based on this idea and on the double dissociation observed in production (Dumont et al., 1999; Foundas et al., 1999; Haaland et al., 2000; Ham et al., 2009; Rapcsak et al., 1993; Roy et al., 1991), differences in cerebral activity during observation and recognition of object-related and non-object-related actions should be expected. In perceptual tasks, neuroanatomical and neuroimaging studies that directly compared objectrelated and non-object-related actions are even more limited (Agnew, Wise, \& Leech, 2012; Pazzaglia, Smania, Corato, \& Aglioti, 2008; Villarreal et al., 2008). Villareal et al. (2008) have reported some differences in the inferior frontal gyrus (IFG) between the action types. However, they have been related to extra-processing demands for non-object-related gesture perception, probably because of the symbolic nature of the gestures presented (e.g. stop, salute, hitch hike, crazy, victory). Recently, Agnew et collaborators (2012) showed different fMRI responses in frontal and parietal cortices during observation of objet-related compared to meaningless non-object-related actions, but results could be due to the use of meaningless actions in the non-related action condition. Indeed, fronto-parietal areas may be more strongly recruited when action processing follows the semantic route, regardless of the type of semantic representation involved. Taken together, patient and fMRI studies have not provided a coherent pattern of data in support of a clear distinction between object-related and non-object-related gesture processing during action production or perception. 
On possible reason for the inconsistencies reported may be that the distinction between object-related and non-object-related actions is relatively fine-grained and more visible on the timing of brain activity within the fronto-parietal network. Accordingly, fMRI paradigms would not be best suited to investigate this issue. Thus, we used EEG measurement and particularly Event-Related Potential method (ERP) to assess the temporal dynamics of object-related and non-object-related action processing during perceptual tasks. With EEG, we could determine the specific moment in processing when differences between action types emerged. It was thus possible to discriminate between effects related to visual complexity occurring at early processing stages and semantic effects occurring at later processing stages. Although the neural correlates of action observation have been importantly studied using EEG techniques (e.g. Silas, Levy, Nielsen, Slade, \& Holmes, 2010 using wholebody movements, Perry \& Bentin, 2009 using hand grasps or Urgen, Plank, Ishiguro, Poizner, \& Saygin, 2013 for comparison between human and non-human motion), to our knowledge no EEG paradigm has explicitly contrasted object-related and nonobject-related actions before.

In light of previous studies, it was critical for our EEG paradigm to control for differences in stimulus complexity between the two action types. Thus, we used point-light display (PLD) stimuli (Johansson, 1973) in order to control for physical differences between stimuli. Indeed, baseline control PLD stimuli were created for each action type, in which the general movement characteristics (duration, number of points and kinematic of points) were equal to the original action but movement information was meaningless. Moreover, PLD stimuli provided biological movement information only - without giving any object visual information in the case of objectrelated action- and minimized context effects. Thus, we are able to test the distinction 
between temporal dynamics of object-related and non-object-related action processing with strictly equivalent stimuli, while controlling for potential differences in stimulus complexity.

Although time-frequency analysis, and in particular mu rhythm modulation, has been successfully used to highlight motor system involvement during observation of PLD of biological movements (Perry \& Bentin, 2011; Perry, Troje, \& Bentin, 2010), mu rhythm modulation would not be expected to be sensitive to semantic differences during action observation. Since the objective of the present study was to distinguish between the semantic processes at play during observation of two types of biological movements, we focused our analysis on ERP components.

Several ERP components have been shown to be sensitive to the observation of PLD presenting whole-body intransitive movements (Hirai, Fukushima, \& Hiraki, 2003; Hirai, Senju, Fukushima, \& Hiraki, 2005; Jokisch, Daum, Suchan, \& Troje, 2005; Krakowski et al., 2011), starting around $200 \mathrm{~ms}$ after stimuli onset. We predicted ERP differences between action types at two stages of PLD visual processing. First, on early visual components (P100 and N170) known to reflect analysis of stimuli physical features (Hirai et al., 2003, 2005; Jokisch et al., 2005), we expected to find differences related to inhomogeneity in stimuli complexity. Second and most critically, differences during perception of the two gesture types were expected on late ERPs components known to be related to object semantic processing. Perception of object-related actions, but not non-object-related actions, would involve the recruitment of some parts of object knowledge, perhaps related to object motor features (Buxbaum et al., 2007; Chao \& Martin, 2000; Martin, 2007). Traditionally, semantic processing has been associated with brain responses occurring around 350$400 \mathrm{~ms}$ after stimulus onset, often identified as N400 component (for instance, 
Balconi \& Caldiroli, 2011; Proverbio \& Riva, 2009; van Elk, van Schie, \& Bekkering, 2010). However, recent studies evidenced that stimulus semantic processing could start earlier. For instance, brain responses associated with semantic tasks (e.g., meaningful/meaningless decision, semantic incongruence detection) on action verbs (Moseley, Pulvermüller, \& Shtyrov, 2013; Pulvermüller, Härle, \& Hummel, 2001), action pictures (Meyer, Harrison, \& Wuerger, 2013) or object pictures (Lloyd-Jones, Roberts, Leek, Fouquet, \& Truchanowicz, 2012; Lu et al., 2010; Proverbio, Adorni, \& D'Aniello, 2011) have been reported as early as $250 \mathrm{~ms}$ after stimulus onset. Thus, ERP components occurring from $250 \mathrm{~ms}$ after stimuli onset were all possible candidates for distinguishing between object-related and non-object-related action processing. In other words, differences during action observation were expected on P3a and/or P3b and/or N400 components.

Finally, we aimed at testing the incidental character of object motor feature selective activation during object-related action processing. To this aim, participants were proposed two distinct tasks. They were instructed either to recognize one given action (specific action recognition task), or to detect the presence of a red point during PLD visual presentation (red point detection task). If object motor feature activation were incidental, ERP differences between object-related and non-related actions would be independent of the requirements of the task.

\section{METHODS}

\subsection{Participants}

Twenty adults (mean age 24.3; age range 19-32; 13 women) participated in the experiment. Data from one participant were removed from the final statistical analysis due to head motion artifacts. The final sample included 19 participants. All 
participants were right-handed (handedness quotients 60-100\%; mean 90\%; Oldfield 1971) and had normal or corrected-to-normal visual acuity. None of the participants reported history of dyslexia or any neurological diseases. The experimental procedure was approved by the local ethical committee in accordance with the Helsinki declaration. All participants signed an informed consent form prior to their participation.

\subsection{Stimuli \& materials}

A Qualysis motion capture system was used in order to capture the motion of one actor in 30 different actions, classified into 2 Action Types: 15 Object-Related Actions (ORA) and 15 Non-Object-Related Actions (NORA). An additional ORA [hammering (a nail)] was recorded in order to serve as the action target in the Specific Action Recognition Task. Action list is presented in Appendix 1. Eighteen reflective markers were attached to the major joints of the actor's body (shoulder, elbow, wrist, thumb, index finger, hip, knee, foot, head and plexus). Motion of these markers was then recorded to create movies of 'point-light' displays (PLD) against a dark background.

It is critical to note that ORA movies resembled pantomimes in the sense that they did not contain objects. However, object-related gestures were actual use actions that were performed by the actor with the object in hand while the motion of the markers positioned on the joints of her body were recorded. Thus, both ORA and NORA movies only presented movements of body in action. Nevertheless, the amount of movement information between the two stimuli categories could have differed (e.g., movements in NORA movies might be of greater amplitude overall). Therefore, control conditions of ORA and NORA stimuli were designed by applying a random transformation on the $\mathrm{x}$ coordinate of each marker before applying a $180^{\circ}$ 
spatial rotation to the movie. Thanks to this procedure, each transformed video had the exact same general movement characteristics (duration, number of point and kinematic of point) as the original video but did not convey any signification. Thus, there were 4 stimulus conditions, 2 Action Types [ORA and NORA] $\times 2$ Display Types [Normal and Transformed], and 15 videos in each condition. Examples of stimuli are presented in Figure 1. Movie duration was set to 1 second. Movies were displayed within a $500 \times 500$ pixels area in the middle of a black screen. Stimulus presentation was controlled by Eprime software version 2.0 run on a PC.

To assess potential behavioral variations in PLD semantic processing, a normative experiment was conducted. Seventeen additional participants viewed the 60 videos and performed a task in which they had to determine as exactly and quickly as possible if the action presented was meaningful or meaningless (for more details about the procedure, see Appendix 2). On the basis of response time (RT) results, 2 items were considered outliers and were excluded from the EEG experiment analysis (1 from each category ORA and NORA: respectively "Opening a tap" and "running") because RT for these items were beyond 2.5 Median Absolute Deviation (MAD) from median RT in their respective condition (Leys et al., 2013). Moreover, on the 28 remaining actions, statistical analyses did not revealed any RT differences between the two Action Types (ORA vs. NORA; $\mathrm{t}_{1,15}=0.962 ; p=0.351$ ). This measure was taken as an index of action subjective semantic processing difficulty (i.e. the more time participants require to decide that a given action is meaningful, the more difficult it is to access some kind of semantic representation of the action). Thus, the two final PLD categories were considered equivalent in terms of semantic processing difficulty. 


\subsection{Procedure}

After a brief presentation of EEG materials and of the general goal of the study, participants were informed that they had to perform two distinct tasks implying the same stimuli: A Red Point Detection task and a Specific Action Recognition task. Task order was counterbalanced between participants. Specific instructions were recalled before each task. During the whole experiment, participants were seated in front of a computer screen $(1600 \times 900,60 \mathrm{~Hz})$ in a dimly illuminated room. They were instructed to keep their gaze fixated on the center of the screen and to answer by pressing on the -space- key of the keyboard.

Prior to the EEG experiment, a familiarization session was administered. The goal of the familiarization session was to clarify the impoverished stimuli that would be presented during the whole EEG experiment. Indeed, videos were simple points in motion, and we wanted to be sure that participants perceived the same actions as those realized by our actor. Thus, each PLD in normal orientation $(15+1$ ORA and 15 NORA) was presented twice during the familiarization session, preceded by the name of the corresponding action (e.g. sawing). Participants had to answer two questions: (1) Are you able to see the person in this video [sawing]? (first presentation) (2) Could you mime the action presented (second presentation)? The same procedure was realized for the 31 actions with signification presented in pseudo-random order. Finally, recognition of the 31 critical PLD was checked right before starting the experimental session. Videos were presented a last time and participants had to name them one at a time. After familiarization, errors were very rare $(2 \%)$. Since the goal of the familiarization session was to ensure agreement on PLD identity before the EEG experiment, participants' responses were systematically corrected. Behavioral 
variability in PLD semantic processing was assessed in a separate normative experiment in which reaction times to PLD semantic categorization were recorded (see 2.2 and Appendix 2).

\subsubsection{Task involving implicit semantic processing: Red-Point Detection}

Specific instructions for the Red-point detection task were: "On each trial, a video of a schematized action will be briefly presented $(1 \mathrm{~s})$. On some trials, one of the white points that compose the schematized action will turn to red. When you detect it, press on the -space- key of the keyboard placed in front of you". This task was called "implicit" because the participant did not need to recognize the action to perform the task. A fixation cross was presented in the center of the screen before and after video presentation. Participants were instructed to fix it in order to minimize blink artifact generated by gaze motion. Inter-trial presentation was set between $3 \mathrm{~s}$ and $4 \mathrm{~s}$ by step of $250 \mathrm{~ms}$. The trial procedure was the same for the 420 trials ( 3 sessions $\times 2$ repetitions $\times 2$ action types $\times 2$ display types $\times 15$ actions +24 trials without video presentation +36 trials in which the red point was presented: $8,6 \%$ of total number of trials). Duration of inter-trials and filler trials (without video presentation) was varied in order to minimize stimuli onset predictability. Trials requiring a behavioral response were used to ensure that participants maintained their attention on the stimuli presented. On those trials, a point-light turned to red during $200 \mathrm{~ms}$ in a random manner between 300 and $700 \mathrm{~ms}$ after video onset. The position of the red point was also randomly determined. Only trials without behavioral response were used for EEG analyses. The duration of the task was about 24 minutes, leading to a total of about 30 minutes including breaks. 


\subsubsection{Task involving explicit semantic processing: Specific Action}

$\underline{\text { Recognition }}$

The Specific Action Recognition task used the exact same procedure as the Red-Point Detection task except that the instructions explicitly required action semantic processing: "On each trial, a video of a schematized action will be briefly presented (1 s). On some trials, the action of "hammering [a nail]" will be shown. When you detect it, press on the -space- key of the keyboard placed in front of you ".

With a total of 420 trials $(3$ sessions $\times 2$ repetitions $\times 2$ action types $\times 2$ display types $\times 15$ actions +24 trials without video presentation +36 trials in which the action "hammering [a nail]" was presented: $8,6 \%$ of total number of trials), the duration of the task was about 24 minutes, leading to a total of about 30 minutes including breaks.

\subsection{Data Acquisition}

EEG was recorded continuously during the two sessions from 128 active electrodes mounted on an elastic cap (10-20 International system Electro-Cap Inc) with an Active Two Biosemi system (Biosemi, Amsterdam, the Netherlands. According to constructor guidelines, all electrode offsets were kept below $20 \mathrm{mV}$. Two additional electrodes were used to monitor eye movements and blinks (one placed at lateral canthi and one below the eyes). Continuous EEG was digitized at $512 \mathrm{~Hz}$ and filtered offline (1-20 Hz) using EEGLAB software (Delorme \& Makeig, 2004) and recalculated to linked mastoid reference. ICA-based artifact correction was used in order to correct blink artifacts (Delorme, Sejnowski, \& Makeig, 2007) ${ }^{1}$.

\footnotetext{
${ }^{1}$ A relatively restrictive bandpass filter of $1-20 \mathrm{~Hz}$ was applied with regard to the ICA-based artifact correction used. While the ICA procedure allows saving trials
} 
Epochs consisting of $200 \mathrm{~ms}$ pre-stimulus and $800 \mathrm{~ms}$ post stimulus were processed separately for each stimulus condition in the two tasks. Epochs contaminated by muscular contractions or an excessive deflection $( \pm 75 \mu \mathrm{V})$ were detected by a visual inspection of the data, and excluded from the averaged ERP waveforms (i.e., on average $5.1 \%$ of trials). Individual subject ERPs were computed on all remaining trials for each condition (about 80 trials), using the $200 \mathrm{~ms}$ pre-stimulus as baseline. In order to generalize results to the items used, a secondary averaging was performed by computing individual item ERPs for each condition (about 110 trials). Based on visual inspection of the scalp map distribution averaged for the 4 conditions ( 2 Action Types $\times 2$ Display Types) in the 2 tasks, we collapsed ERPs across 8, 11 and 12 electrodes to represent maximal left and right posterior activity respectively for P100, N170 and P3b. A similar procedure was adopted for P3a and N400, where maximal anterior activity was represented by the average signal across 12 and 25 electrodes, respectively (see Figure 2 for more detail about ROI definition).

Insert Figure 2 about here $>$

Mean Peak Amplitude for each component was computed by averaging the signal according to a window centered on the maximum peak. Maximum peak was determined using the mean signal (irrespective of task, subject, region and stimuli presentation). In order to adapt mean amplitude computation to the shape of each component, window size was $20 \mathrm{~ms}$ (10 ms on both sides of the maximum peak) for

contaminated by blink artifacts (and thus computing ERPs based on a maximum of trials), it is very sensitive to linear drifts and results in poor decomposition when linear drifts are present in the raw data (Debener, Thorne, Schneider, \& Campos Viola, 2010). Thus, a $1 \mathrm{~Hz}$ filter was required to remove linear drifts before applying the ICA procedure. 
P100 and N170 components, $60 \mathrm{~ms}$ for P3a component and $100 \mathrm{~ms}$ for P3b and N400 components. The percentage of individual peaks contained in each time window was $74 \%$ for $\mathrm{P} 100,42 \%$ for $\mathrm{N} 170,74 \%$ for $\mathrm{P} 3 \mathrm{a}$, and $68 \%$ for $\mathrm{P} 3 \mathrm{~b}$.

In order to localize the regions specifically involved in the generation of each component, we performed a Low-Resolution Electromagnetic Tomography (sLORETA; Pascual-Marqui, 2002) on the ERP waveforms at each time window. In this study, an improved version of this algorithm was used (called SLORETA) on the group data independently for each of the 4 stimuli conditions ( 2 Action Types $\times 2$ Display Types). Images of electric neuronal activity were derived from the surface electrodes using a three-shell spherical head model. Current source densities were estimated from these images for each of the 6,430 voxels in the MNI space (Montreal Neurological Institute), each voxel representing $5 \mathrm{~mm} 3$ of brain tissue. The procedure was used to provide additional information about the possible sources of the ERP differences observed. Thus, source localization maps will be presented only for ERPs that exhibit differences between action types, after controlling for their respective baseline.

\subsection{Data Analysis}

First, although task order was counterbalanced during the experiment and was not a factor of interest, we verified that it did not have any major effect on EEG data (as witnessed by either a main effect of order or an interaction between order and task) before removing this factor from the analyses.

\subsubsection{Main Analysis}

In order to directly highlight the components that differ in the visual processing of the two Action Types while controlling for potential differences in 
motion quantity between stimuli, we conducted analyses on the signal difference between Normal and Transformed Display Types for each ERP component. With this procedure, the variables Action Types (ORA and NORA) and Display Types (Normal and Transformed) were replaced by a single variable: Action Type Corrected $($ ORAc $=$ ORA Normal - ORA Transformed, and NORAc $=$ NORA Normal - NORA Transformed). Thus, a Task (Explicit vs. Implicit) $\times$ ROI (Right vs. Left $) \times$ Action Type Corrected (NORAc vs. ORAc) Analysis of Variance (ANOVA) was computed on the Mean Peak Amplitude of P100, N170 and P3b components. Similarly, a Task $($ Explicit vs. Implicit) $\times$ Action Type Corrected (NORAc vs. ORAc) ANOVA was computed on the Mean Peak Amplitude of P3a and N400 components. Finally, planned comparisons were used to directly contrast the effect of the two action types (NORAc vs. ORAc) on response amplitude in each task and/or region of interest.

If differences in visual processing of object-related and non-object-related actions do exist, we should observe a main effect of Action Type Corrected, or an interaction between Action Type Corrected and Task and/or ROI, on the Mean Peak Amplitude of at least one ERP component. In particularly, we expected differences on relatively late ERPs components (after $250 \mathrm{~ms}$ ) devoted to higher-level visuosemantic processing.

\subsubsection{Complementary Analysis}

Secondarily, we ran analyses on Mean Peak Amplitude of P100, N170, P3a, P3b, and N400 components while keeping Action Type and Display Type variables separated. This was done in order to evaluate potential effects that were not of primary interest, but that could provide further information for the interpretation of effects tested in the main analysis. In particular, effects of Action Type (ObjectRelated vs. Non-Object-Related) regardless of Display Type (both Normal and 
Transformed) could inform about low-level visual differences between object-related and non-object-related actions.

Thus, a Task (Explicit vs. Implicit) $\times$ ROI (Right vs. Left $) \times$ Action Type $($ NORA vs. ORA $) \times$ Display Type (Normal vs. Transformed) ANOVA was conducted on the Mean Peak Amplitude of P100, N170 and P3b components. Similarly, a Task $($ Explicit vs. Implicit) $\times$ Action Type $($ NORA vs. ORA $) \times$ Display Type $($ Normal vs Transformed) ANOVA was computed on the Mean Peak Amplitude of P3a and N400 components. Finally, response amplitudes for the two action types were directly contrasted using planned comparisons.

\section{Results}

Main results are presented in Figure 3. Below are presented the results of the analyses on the individual subject ERPs (variability between subjects). Note that the same pattern of results is visible in the analysis on individual item ERPs (variability between items, all significant $\mathrm{p}$-values $<.05$ ).

\subsection{Main results}

\subsubsection{P100 and N170 component (20ms)}

The ANOVA did not show any main effect of Action Type Corrected on Mean Peak Amplitude of the P100 and N170 components (all F < 1). Furthermore, Action Type Corrected did not interact with Task on Mean Peak Amplitude of the P100 component, alone or combined with Region (respectively $\mathrm{F}_{1,18}=1.371 ; p=$ 0.257 and $\left.F_{1,18}=1.295 ; p=0.27\right)$. Similarly, results were non-significant on Mean Peak Amplitude of the N170 component (respectively $\mathrm{F}_{1,18}=2.594 ; p=0.125$ and $\mathrm{F}_{1,18}=2.01 ; p=0.173$ for interaction with Task alone or with Task and Region) 


\subsubsection{P3a component (60ms)}

The ANOVA revealed a significant main effect of Action Type Corrected on Mean Peak Amplitude of the P3a component $\left(\mathrm{F}_{1,18}=10.63 ; p<0.01\right)$. Specifically, P3a amplitude was greater when participants perceived Objet-Related Actions compared to Non-Object-Related Actions, and this difference could not be attributed to low-level differences between stimuli (Figure 3a and 3b). Besides, Action Type Corrected did not interact with Task on Mean Peak Amplitude of the P3a component $(\mathrm{F}<1)$. Insert Figure 3 about here

\subsection{3. $P 3 b(100 \mathrm{~ms})$}

The ANOVA showed a marginal Region $\times$ Action Type Corrected interaction on Mean Peak Amplitude of the P3b component $\left(\mathrm{F}_{1,18}=4.18 ; p=0.056\right)$. However, pairwise comparisons did not reveal any significant difference between ORAc and NORAc stimuli in the left $\left(\mathrm{t}_{18}=-0.32, p=0.75\right)$ or in the right posterior ROI $\left(\mathrm{t}_{18}=\right.$ 0.84, $p=0.41)$. Furthermore, Action Type Corrected did not interact with Task on Mean Peak Amplitude of the P3b component, alone or combined with Region (respectively $\mathrm{F}_{1,18}=0.23 ; p=0.64$ and $\mathrm{F}_{1,18}=0.588 ; p=0.453$ ).

\subsection{4. $\mathrm{N} 400(100 \mathrm{~ms})$}

The ANOVA did not highlight any main effect of Action Type Corrected on Mean Peak Amplitude of the N400 component $(\mathrm{F}<1)$. Furthermore, Action Type Corrected did not interact with Task on Mean Peak Amplitude of the N400 
component $\left(\mathrm{F}_{1,18}=2.75 ; p=0.115\right)$.

\subsection{Complementary Results}

\subsubsection{Action Type effects}

When Action Type and Display Type were considered separately, a main effect of Action Type was observed on Mean Peak Amplitude of the N170 and P3a components (respectively $\mathrm{F}_{1,18}=7.032 ; p<0.05$ and $\mathrm{F}_{1,18}=16.88 ; p<0.001$ ). Mean Peak Amplitude of the N170 component was significantly greater when participants perceived Objet-Related Actions compared to Non-Object-Related Actions, independently of Display Type (both Normal and Transformed), Region or Task.

In a similar line, there was a significant Region $\times$ Action Type interaction on Mean Peak Amplitude of the P100 and P3b components (respectively $\mathrm{F}_{1,18}=11.82 ; p$ $<0.01$ and $\left.\mathrm{F}_{1,18}=6.59 ; p<0.05\right)$. For the P100 component, planned comparisons showed that ORA P100 amplitude was greater than NORA P100 amplitude in the right $\left(\mathrm{t}_{18}=2.58, p<0.05\right)$, but not in the left posterior ROI $\left(\mathrm{t}_{18}=-0.18, p=0.85\right)$. For P3b, the reverse pattern of results was observed: ORA P3b amplitude was smaller than NORA P3b amplitude in the left $\left(\mathrm{t}_{18}=-2.53, p<0.05\right)$, but not in the right posterior ROI $\left(\mathrm{t}_{18}=-0.92, p=0.37\right)$.

\subsubsection{Task effects}

A main effect of Task was visible on the Mean Peak Amplitude of the P3a and N400 components $\left(\mathrm{F}_{(1,18)}=10.42 ; p<0.05\right.$ and $\mathrm{F}_{(1,18)}=6.39 ; p<0.05$, respectively). Results showed that Mean Peak Amplitude of the P3a component was greater when the task involved an implicit semantic processing compared to an explicit one. Inversely, Mean Peak Amplitude of the N400 component was greater when the task involved an explicit semantic processing compared to an implicit one. 


\subsection{Source Visualization}

Probable sources of the P3a component in the different conditions using sLORETA are displayed in Figure 3c. As shown by Figure 3c, P3a probable source generator computed with sLORETA software was identified within a large frontotemporo-parietal network. However, visual inspection of the probable sources for the two action types and their respective control baselines suggests relative fine differences between P3a sources across conditions. Indeed, the most probable source for non-object related actions is observed in the left inferior frontal cortex (around BA 44), whereas the most probable source for object-related actions is situated in the left parietal cortex (around BA 40).

\section{DisCUSSION}

The main goal of the present work was to investigate whether transitive (object-related) and intransitive (non-object-related) gestures relied on distinct cognitive and neural mechanisms. Based on the assumption that regardless of gesture type, action execution and observation neural circuits largely overlap in several regions of the fronto-parietal cortex (for review, see Caspers et al., 2010; Rizzolatti \& Craighero, 2004 but see Hickok \& Hauser, 2010; Kalénine et al., 2010; Mahon \& Caramazza, 2008 for nuances), we evaluated to what extent object-related or nonobject-related actions involved distinct processes within this network using perceptual tasks. Thanks to the high temporal resolution of EEG/ERP recordings, we were able to identify temporal differences in the perception of the two action types at the neural level. The main results revealed a significant difference between object-related and non-object-related action perception on the amplitude of the P3a component. Perception of point-light displays depicting objet-related actions lead to a greater P3a 
response than perception of point-light displays depicting non-object-related actions. In the following section, we will argue that the differences observed between the two action types do not only reflect differences in low-level visual features or attentional processes, but rather suggest that object-related actions involved the additional mobilization of some object features. The exact nature of the features recruited will be debated, and additional arguments from source localization results will be presented. Finally, the incidental character of object motor feature activation will be discussed according to the pattern of task-related effects observed.

\subsection{Differences between Object-Related and Non-Object-Related Action} perception cannot be explained by low-level visual features

The main difference between Object-Related and Non-Object-Related Actions was observed after comparison with baseline conditions that controlled for low-level visual differences between stimuli, such as the amount of movement information. Thus, we are fairly confident that the neural difference observed during action processing does not simply reflect potential differences in visual complexity between object-related and non-object-related actions, an alternative hypothesis that could not have been ruled out in previous studies (Agnew et al., 2012; Villarreal et al., 2008). Discrepancies between studies are probably due to differences in the stimuli used. Indeed, in our study object-related and non-object related actions only differed on the existence of a relation between action kinematics and object use. Conversely, the contrast between object-related and non-object-related actions overlapped with the distinction between meaningful and meaningless gestures in Agnew et al. (2012), and with the difference between symbolic and non-symbolic gestures in Villarreal et al. (2008). Yet, our results are in line with theoretical developments arguing that object- 
related and non-object-related actions are supported by distinct processes (Haaland et al., 2000; Ham et al., 2010; Rapcsak et al., 1993; Roy et al., 1991).

Additional results highlighted direct differences between the two action types (before subtraction with baseline) on several ERP components (P100, N170, P3a and P3b). Direct differences between action types were expected in the case of low-level physical differences between stimuli. Indeed, our data showed that the mean peak amplitude of the N170 component evoked by object-related actions was significantly greater than the one evoked by non-object-related actions. A similar pattern of results was also present for the P100 component, but only in the right posterior region. Sensitivity of early ERP components to whole-body movements has already been investigated (Hirai et al., 2003, 2005; Hirai \& Hiraki, 2006; Jokisch et al., 2005; VirjiBabul, Cheung, Weeks, Kerns, \& Shiffrar, 2007). Classically, the positive component observed at occipital sites around 100-130 ms after stimulus presentation (P100) is associated with form-processing mechanisms (Bach \& Ullrich, 1997; Jokisch et al., 2005), whereas the negativity occurring closely after around 150-300 ms after stimulus presentation (called N170 or N200) is supposed to represent motion processing (Hirai et al., 2003; 2005, 2006; Jokisch et al., 2005). Thus, the effect observed on the P100 could reflect physical differences in our stimuli, in particular in the number of points presented and/or their spatial configuration in the first frame. The effect observed on the later components (N170 and P3b) could be related to motion quantity differences between the two action types. Overall, point-light displays representing non-object-related actions involved more body segments than object-related actions, implying difference in quantity of points in motion. Even if all stimuli depicted biological kinematics, subtle motion quantity differences likely impacted components involved in motion processing occurring between 150 and 
300 ms (Hirai et al., 2003; 2005, 2006; Jokisch et al., 2005).

In sum, by contrasting action types before and after subtraction with the appropriate baseline, it was possible to disentangle the effects related to low-level stimulus differences between the two action types (observed on P100 and N170) from the effects related to differences in early semantic processing (observed on P3a).

\subsection{Differences between Object-Related and Non-Object-Related Action perception are not driven by the sample of intransitive actions used}

The goal of the present study was to contrast ORA and NORA as a whole, without further clustering of non-object-related actions. Therefore, a wide range of NORA was selected, irrespective of the $\operatorname{limb}(\mathrm{s})$ involved, the symbolic aspect, the action valence, etc. (see stimulus list in Appendix 1). Nonetheless, one could object that differences between ORA and NORA are driven by a subtype of NORA exemplars. In order to verify that this is not the case, we conducted a complementary by-item analysis, i.e. averaging the ERPs over participants and considering variability between items. The same results were visible in the by-item analysis, confirming that the results can be generalized to all NORA and ORA items. Future studies may further evaluate the existence of ERP differences on P3a component between various ORA and NORA subtypes.

\footnotetext{
4.3. Differences between Object-Related and Non-Object-Related Actions are not likely related to variations in attentional resource allocation

In the attentional literature, the P3a component is classically related to the “oddball” effect (Kok, 2001; Picton, 1992; Polich, 2007). In the oddball paradigm, a deviant stimulus presented in a homogeneous series causes an important increase of
} 
P3a amplitude around $300 \mathrm{~ms}$ after stimulus onset. Deviance can apply to a wide range of stimulus characteristics such as novelty, salience, semantic incongruence, etc. In our study, the only potentially deviant stimuli were the target stimuli to be detected (i.e. red-point PLD or hammering [a nail] action) for which manual responses were recorded, and data excluded. In addition, PLD in the two action type conditions were submitted to the same number of repetitions, leading to equally homogeneous series. Thus, P3a differences do not reasonably reflect variations in deviance detection here.

More generally, P300 has been associated to resource allocation, processing capacity and task difficulty (Kok, 2001; Picton, 1992; Polich, 2007). One could argue that object-related actions are more complex to identify at the basic level (e.g. sawing, drinking from a cup, etc.) than non-object-related actions and consequently, that their recognition require more processing capacities, as reflected by stronger P3a involvement. Even if our normative experiment showed that semantic categorization was equivalent between the two action types in terms of difficulty, action naming was not involved, like in the EEG experiment. Thus, basic-level action identification was not directly tested. Moreover, although participants named all actions before the EEG experiment, we cannot exclude the possibility that basic-level identification remained easier for one category compared to the other after familiarization. During the EEG experiment, participants might have engaged in such basic-level identification when performing the specific action recognition task ("detecting the hammering [a nail] action"), which may have put more load on the attentional system. Yet similar P3a differences between action types were observed in the Red Point Detection Task, where semantic processing was not required at all. It is always possible that participants implicitly performed basic-level action identification while detecting the 
color change in the stimuli, but this hypothesis remains relatively unlikely, considering its additional cognitive cost.

\subsection{Differences between action types on the P3a component possibly reflect mobilization of object motor features}

Activation of object motor features during perception of static object pictures was the focus of a recent EEG study (Proverbio, Adorni, \& D'Aniello, 2011). Proverbio and collaborators reported differences in brain activity during perception of manipulable and non-manipulable objects starting from $210-270 \mathrm{~ms}$ after stimulus onset (component referred to as "anterior negativity") and continuing at 550-600 ms (component referred to as "P300"). In both time windows, they observed a larger response, particularly in the left hemisphere, when participants perceived objects associated with a specific action manipulation (e.g. hammer, screwdriver or keyboard for instance), as compared to less manipulable objects (e.g. carpet or piece of pottery). Interestingly, the difference we observed during perception of object-related and nonobject-related actions became visible in the $200-300 \mathrm{~ms}$ time window. Thus, object manipulability and action transitivity seem to influence brain activity with a similar timing, suggesting that both situations involve the recruitment of additional object motor features.

The findings reported here strongly suggest that object-related and non objectrelated action processing differs at the neural level. However, the difference was observed during action observation and any generalization to action performance must be cautious. Although there is important evidence that regardless of gesture type, action execution and observation neural circuits largely overlap in several regions of the fronto-parietal cortex (for review, see Caspers, Zilles, Laird, \& 
Eickhoff, 2010; Rizzolatti \& Sinigaglia, 2010), neural circuits are not fully equivalent and we might not observe the same exact processes at play when executing objectrelated and non-object related actions (Hickok \& Hauser, 2010; Kalénine, Buxbaum, \& Coslett, 2010; Mahon \& Caramazza, 2008). As mentioned earlier, one challenge to assess this hypothesis is to find a way to execute object-related actions without involving objects or pantomimes.

Another remaining issue concerns the nature of the specific knowledge recruited. While the result pattern strongly suggests that the neural difference observed between the two action types reflects the additional involvement of object features, it is also possible that they activate different body-part representations. Indeed, NORA may involve whole-body representations more frequently, whereas ORA are tool-use actions that are tied to hand representations. Several studies suggest that action and body representations (and in particular tool-use gestures and hand representations) recruit very similar brain areas within the motor system (Buxbaum \& Saffran, 2002; Carota, Moseley, \& Pulvermüller, 2012; Hauk, Johnsrude, \& Pulvermüller, 2004; Tettamanti et al., 2005). Our paradigm does not allow distinguishing between body-related and gesture-related representations. Thus, ORA may involve both object-related and hand-related representations to a greater extend than NORA. Moreover, motor features may not be the only part of object knowledge activated during ORA observation. Other object features, such as object shape or object function, may also be recruited. The difference in the probable source of the EEG response to the two action types might provide additional discussion elements to this issue.

\subsection{Probable sources of EEG responses suggest differences between}




\section{object-and non-object-related-action processing within the fronto-parietal network}

As shown by Figure 3c, a large fronto-temporo-parietal network seems to be recruited during action observation independently from action characteristics. However, a subset of probable sources would be specific to the action type considered. Qualitatively, comparing the probable sources of the two action types with their respective controls suggests that the left inferior frontal cortex (around BA $44)$ is the most probable source for non-object related actions, whereas the left parietal cortex (around BA 40) would be the most probable source for object-related actions. These two regions are considered important parts of the visuo-motor system and have already been highlighted as critically involved in action recognition (Kalénine et al., 2010; Pazzaglia et al., 2008). In our study, activation of the visuomotor system during visual perception of actions was expected, even if actions were summarized by point lights in motion (Perry, Troje, \& Bentin, 2010; Saygin, Wilson, Hagler, Bates, \& Sereno, 2004; Ulloa \& Pineda, 2007). As suggested by Saygin and collaborators, the recruitment of the visuo-motor system during perception of simplified stimuli such as PLD allowed participants to "fill in" or to reconstruct the meaning of the impoverished visual input.

The presence of a left parietal source in the case of object-related action processing, which was not visible during non-object related action processing, is particularly interesting. The left parietal cortex is an important region of the visuomotor system and a critical part of the dorsal stream (Milner \& Goodale, 1995; Ungerleider \& Mishkin, 1982). Within the dorsal stream, a specific pathway has been recently identified for planning actions based on conceptual representations, i.e. the dorso-ventral stream (Buxbaum \& Kalénine, 2010; Pisella, Binkofski, Lasek, Toni, \& 
Rossetti, 2006; Rizzolatti \& Matelli, 2003). The probable source of the P3a response for object-related actions seems to cover most part of the left inferior parietal cortex, a key area of the dorso-ventral pathway that would support gesture representations. Thus, results from the source localization are compatible with the hypothesis that object-related action perception involves additional activation of object motor features, alone or in combination with other parts of object knowledge.

\subsection{Object knowledge recruitment during object-related action}

\section{processing is incidental}

Another important result is the fact that we observed a difference between action types on the P3a component independently from the implicit or explicit character of the semantic processing induced by the task. Nevertheless, we observed a main effect of Task on the P3a and N400 components indicating that overall, the amplitude of these components significantly differed between implicit and explicit semantic processing. The influence of the type of task on these late components - and not on earlier components- reinforces the idea that P3a and N400 components reflect high-level (semantic) action processing.

There was no interaction between Task and Action Type Corrected factors on the mean amplitude of the P3a component. Thus, it seems that the recruitment of object knowledge during PLD action processing is incidental and does not require explicit action recognition. Based on lesion studies, Pisella and colleagues (2006) have already suggested that activation of the distributed network likely supporting tool knowledge (concentrated in the left hemisphere) should be observed independently from the modality of stimulus presentation (image, word presented visually or auditory) and/or to task (object naming, object-action matching task, 
passive object perception). All happens as if independently of the task required, object-related actions automatically activated associated object knowledge.

\subsection{Conclusion}

The present study highlights neural activity differences between perception of object-related and non-object-related actions. Using the high temporal resolution of EEG recordings, we could identify that the difference occurred around $250 \mathrm{~ms}$ after onset of action visual processing, and that it was probably related to a differential recruitment of fronto-parietal regions. This result cannot by explained by low-level visual feature differences between action types and is not likely related to variations in attentional resource allocation. Instead, the ERP difference possibly reflects incidental activation of object knowledge in the case of object-related actions. Although results are compatible with the activation of object motor features during action perception, the issue of the exact nature of the attributes recruited remains for further research.

\section{ACKNOWLEDGEMENT}

This work was funded by the French National Research Agency (ANR-11-PDOC0014, ANR-11-EQPX-0023) and also supported by European funds through the program FEDER SCV-IrDIVE. Authors thank the 37 volunteers for their participation in the study and Yann Coello for precious comments on the experiment design.

\section{REFERENCES}

Agnew, Z. K., Wise, R. J. S., \& Leech, R. (2012). Dissociating object directed and non-object directed action in the human mirror system; implications for theories 
of motor simulation. PloS one, 7(4), e32517.

Bach, M., \& Ullrich, D. (1997). Contrast dependency of motion-onset and patternreversal VEPs: Interaction of stimulus type, recording site and response component. Vision Research, 37(13), 1845-1849.

Balconi, M., \& Caldiroli, C. (2011). Semantic violation effect on object-related action comprehension. N400-like event-related potentials for unusual and incorrect use. Neuroscience, 197, 191-199.

Bohlhalter, S., Hattori, N., Wheaton, L., Fridman, E., Shamim, E. A., Garraux, G., \& Hallett, M. (2009). Gesture subtype-dependent left lateralization of praxis planning: an event-related fMRI study. Cerebral cortex, 19(6), 1256-62.

Buxbaum, L. J. (2001). Ideomotor apraxia: a call to action. Neurocase, 7(6), 445-58.

Buxbaum, L. J., \& Kalénine, S. (2010). Action knowledge, visuomotor activation, and embodiment in the two action systems. Annals of the New York Academy of Sciences, 1191, 201-18.

Buxbaum, L. J., Kyle, K., Grossman, M., \& Coslett, H. B. (2007). Left inferior parietal representations for skilled hand-object interactions: evidence from stroke and corticobasal degeneration. Cortex, 43(3), 411-23.

Buxbaum, L. J., \& Saffran, E. M. (2002). Knowledge of object manipulation and object function: Dissociations in apraxic and nonapraxic subjects. Brain and Language, 82, 179-199.

Carmo, J. C., \& Rumiati, R. I. (2009). Imitation of transitive and intransitive actions in healthy individuals. Brain and cognition, 69(3), 460-4.

Carota, F., Moseley, R., \& Pulvermüller, F. (2012). Body-part-specific Representations of Semantic Noun Categories. Journal of Cognitive Neuroscience, 24(6), 1492-509.

Caspers, S., Zilles, K., Laird, A. R., \& Eickhoff, S. B. (2010). ALE meta-analysis of action observation and imitation in the human brain. NeuroImage, 50(3), 11481167.

Chao, L. L., \& Martin, A. (2000). Representation of manipulable man-made objects in the dorsal stream. NeuroImage, 12(4), 478-84.

Cubelli, R., Marchetti, C., Boscolo, G., \& Della Sala, S. (2000). Cognition in Action: Testing a Model of Limb Apraxia. Brain and Cognition, 44(2), 144-165.

Culham, J. C. (2004). Human brain imaging reveals a parietal area specialized for grasping. In N. Kanwisher \& J. Duncan (Eds.), Attention and Performance XX: Functional Brain Imaging of Visual Cognition. (Oxford Uni., pp. 417-438). Oxford.

Culham, J. C., Danckert, S. L., DeSouza, J. F. X., Gati, J. S., Menon, R. S., \& Goodale, M. A. (2003). Visually guided grasping produces fMRI activation in dorsal but not ventral stream brain areas. Experimental brain research, 153(2), $180-9$.

Debener, S., Thorne, J., Schneider, T. R., \& Campos Viola, F. (2010). Using ICA for the analysis of Multi-Channel EEG data. In M. Ullsperger \& S. Debener (Eds.), Simultaneous EEG and fMRI: recording, analysis and application (pp. 121-133). Oxford University Press. 
Delorme, A., \& Makeig, S. (2004). EEGLAB: an open source toolbox for analysis of single-trial EEG dynamics including independent component analysis. Journal of Neuroscience Methods, 134(1), 9-21.

Delorme, A., Sejnowski, T., \& Makeig, S. (2007). Enhanced detection of artifacts in EEG data using higher-order statistics and independent component analysis. NeuroImage, 34(4), 1443-49.

Dumont, C., Ska, B., \& Schiavetto, A. (1999). Selective impairment of transitive gestures: An unusual case of apraxia. Neurocase, 5(5), 447-458.

Foundas, A. L., Macauley, B. L., Raymer, A. M., Maher, L. M., Heilman, K. M., \& Gonzalez Rothi, L. J. (1995). Ecological implications of limb apraxia: evidence from mealtime behavior. Journal of the International Neuropsychological Society : JINS, 1(1), 62-6.

Frey, S. H. (2007). What puts the How in Where? Tool use and the divided visual streams hypothesis. Cortex, 43(3), 368-375.

Fridman, E. A., Immisch, I., Hanakawa, T., Bohlhalter, S., Waldvogel, D., Kansaku, K., ... Hallett, M. (2006). The role of the dorsal stream for gesture production. NeuroImage, 29(2), 417-428.

Gonzalez Rothi, L. J., Ochipa, C., \& Heilman, K. M. (1991). A Cognitive Neuropsychological Model of Limb Praxis. Cognitive Neuropsychology, 8(6), 443-458.

Gut, M., Urbanik, A., Forsberg, L., Binder, M., Rymarczyk, K., Sobiecka, B., ... Grabowska, A. (2007). Brain correlates of right-handedness. Acta neurobiologiae experimentalis, 67(1), 43-51.

Haaland, K. Y., Harrington, D. L., \& Knight, R. T. (2000). Neural representations of skilled movement. Brain, 123 (Pt 11), 2306-13.

Ham, H. S., Bartolo, A., Corley, M., Swanson, S., \& Rajendran, G. (2010). Case report: selective deficit in the production of intransitive gestures in an individual with autism. Cortex, 46(3), 407-9.

Hickok, G., \& Hauser, M. (2010). (Mis)understanding mirror neurons. Current biology, 20(14), R593-4.

Hirai, M., Fukushima, H., \& Hiraki, K. (2003). An event-related potentials study of biological motion perception in humans. Neuroscience Letters, 344(1), 41-44.

Hirai, M., \& Hiraki, K. (2006). The relative importance of spatial versus temporal structure in the perception of biological motion: an event-related potential study. Cognition, 99(1), B15-29.

Hirai, M., Senju, A., Fukushima, H., \& Hiraki, K. (2005). Active processing of biological motion perception: an ERP study. Brain research. Cognitive brain research, 23(2-3), 387-96.

Johansson, G. (1973). Visual perception of biological motion and a model for its analysis. Perception \& Psychophysics, 14(2), 201-211.

Johnson-frey, S. H., Newman-norlund, R., \& Grafton, S. T. (2005). A Distributed Left Hemisphere Network Active During Planning of Everyday Tool Use Skills. Cerebral Cortex, 15(6), 681-695.

Jokisch, D., Daum, I., Suchan, B., \& Troje, N. F. (2005). Structural encoding and 
recognition of biological motion: evidence from event-related potentials and source analysis. Behavioural brain research, 157(2), 195-204.

Kalénine, S., Buxbaum, L. J., \& Coslett, H. B. (2010). Critical brain regions for action recognition: Lesion-symptom mapping in left hemisphere stroke Running title : Action recognition in stroke. Brain, 133(11), 3269-3280.

Kok, A. (2001). On the utility of P3 amplitude as a measure of processing capacity. Psychophysiology, 38(3), 557-577.

Krakowski, A. I., Ross, L. a, Snyder, A. C., Sehatpour, P., Kelly, S. P., \& Foxe, J. J. (2011). The neurophysiology of human biological motion processing: a highdensity electrical mapping study. NeuroImage, 56(1), 373-83.

Króliczak, G., Cavina-Pratesi, C., Goodman, D. A., \& Culham, J. C. (2007). What does the brain do when you fake it? An FMRI study of pantomimed and real grasping. Journal of neurophysiology, 97, 2410-2422.

Króliczak, G., \& Frey, S. H. (2009). A common network in the left cerebral hemisphere represents planning of tool use pantomimes and familiar intransitive gestures at the hand-independent level. Cerebral cortex, 19(10), 2396-410.

Liepmann, H. (1908). Drei aufsatze aus dem apraxiegebiet (Karger). Berlin.

Lloyd-Jones, T. J., Roberts, M. V, Leek, E. C., Fouquet, N. C., \& Truchanowicz, E. G. (2012). The time course of activation of object shape and shape+colour representations during memory retrieval. PloS one, 7(11), e48550.

Lu, A., Xu, G., Jin, H., Mo, L., Zhang, J., \& Zhang, J. X. (2010). Electrophysiological evidence for effects of color knowledge in object recognition. Neuroscience Letters, 469, 405-410.

Mahon, B. Z., \& Caramazza, A. (2008). A critical look at the embodied cognition hypothesis and a new proposal for grounding conceptual content. Journal of Physiology-Paris, 102(1), 59-70.

Martin, A. (2007). The representation of object concepts in the brain. Annual review of psychology, 58(August), 25-45.

Meyer, G. F., Harrison, N. R., \& Wuerger, S. M. (2013). The time course of auditoryvisual processing of speech and body actions: Evidence for the simultaneous activation of an extended neural network for semantic processing. Neuropsychologia, 51, 1716-1725.

Milner, A. D., \& Goodale, M. A. (1995). The Visual Brain in Action. (O. U. Press, Ed.). Oxford.

Moseley, R., Pulvermüller, F., \& Shtyrov, Y. (2013). Sensorimotor semantics on the spot: brain activity dissociates between conceptual categories within $150 \mathrm{~ms}$. Scientific reports, 3, 1928.

Mozaz, M., Rothi, L. J. G., Anderson, J. M., Crucian, G. P., \& Heilman, K. M. (2002). Postural knowledge of transitive pantomimes and intransitive gestures. Journal of the International Neuropsychological Society: JINS, 8(7), 958-62.

Pascual-Marqui, R. D. (2002). Standardized low-resolution brain electromagnetic tomography (sLORETA): technical details. Methods and findings in experimental and clinical pharmacology, 24 Suppl D, 5-12.

Pazzaglia, M., Smania, N., Corato, E., \& Aglioti, S. M. (2008). Neural underpinnings 
of gesture discrimination in patients with limb apraxia. The Journal of neuroscience, 28(12), 3030-41.

Perry, A., \& Bentin, S. (2009). Mirror activity in the human brain while observing hand movements: A comparison between EEG desynchronization in the $\mu$-range and previous fMRI results. Brain Research, 1282, 126-132.

Perry, A., \& Bentin, S. (2011). Motor system contributions to our understanding of others: Evidence from EEG activity in the mu frequency range. Journal of Molecular Neuroscience, 45, S92.

Perry, A., Troje, N. F., \& Bentin, S. (2010). Exploring motor system contributions to the perception of social information: Evidence from EEG activity in the $\mathrm{mu} / \mathrm{alpha}$ frequency range. Social neuroscience, 5(3), 272-84.

Picton, T. W. (1992). The P300 wave of the human event-related potential. Journal of clinical neurophysiology: official publication of the American Electroencephalographic Society, 9(4), 456-479.

Pisella, L., Binkofski, F., Lasek, K., Toni, I., \& Rossetti, Y. (2006). No doubledissociation between optic ataxia and visual agnosia: multiple sub-streams for multiple visuo-manual integrations. Neuropsychologia, 44(13), 2734-48.

Polich, J. (2007). Updating P300: An Integrative Theory of P3a and P3b. Clinical neurophysiology, 118(10), 2128-2148.

Proverbio, A. M., Adorni, R., \& D’Aniello, G. E. (2011). 250 Ms To Code for Action Affordance During Observation of Manipulable Objects. Neuropsychologia, 49(9), 2711-7.

Proverbio, A. M., \& Riva, F. (2009). RP and N400 ERP components reflect semantic violations in visual processing of human actions. Neuroscience Letters, 459(3), 142-146.

Pulvermüller, F., Härle, M., \& Hummel, F. (2001). Walking or talking? Behavioral and neurophysiological correlates of action verb processing. Brain and language, $78,143-168$.

Rapcsak, S. Z., Ochipa, C., Beeson, P. M., \& Rubens, A. B. (1993). Praxis and the right hemisphere. Brain and cognition, 23(2), 181-202.

Rizzolatti, G., \& Matelli, M. (2003). Two different streams form the dorsal visual system: anatomy and functions. Experimental brain research, 153(2), 146-57.

Rizzolatti, G., \& Sinigaglia, C. (2010). The functional role of the parieto-frontal mirror circuit: interpretations and misinterpretations. Nature reviews. Neuroscience, 11, 264-274.

Roy, E. A., Square-Storer, P., Hogg, S., \& Adams, S. (1991). Analysis of task demands in apraxia. The International journal of neuroscience, 56(1-4), 177-86.

Saygin, A. P., Wilson, S. M., Hagler, D. J., Bates, E., \& Sereno, M. I. (2004). Pointlight biological motion perception activates human premotor cortex. The Journal of neuroscience, 24(27), 6181-8.

Senkfor, A. J. (2008). Memory for pantomimed actions versus actions with real objects. Cortex, 44, 820-833.

Silas, J., Levy, J. P., Nielsen, M. K., Slade, L., \& Holmes, A. (2010). Sex and individual differences in induced and evoked EEG measures of action 
observation. Neuropsychologia, 48(9), 2417-2426.

Tettamanti, M., Buccino, G., Saccuman, M. C., Gallese, V., Danna, M., Scifo, P., ... Perani, D. (2005). Listening to action-related sentences activates fronto-parietal motor circuits. Journal of Cognitive Neuroscience, 17, 273-281.

Ulloa, E. R., \& Pineda, J. A. (2007). Recognition of point-light biological motion: mu rhythms and mirror neuron activity. Behavioural brain research, 183(2), 188-94.

Ungerleider, L. G., \& Mishkin, M. (1982). Two cortical visual systems. In D. J. Ingle, M. A. Goodale, \& R. J. W. Manfield (Eds.), Analysis of Visual Behavior (MIT Press.). Cambridge, MA.

Urgen, B. A, Plank, M., Ishiguro, H., Poizner, H., \& Saygin, A. P. (2013). EEG theta and $\mathrm{Mu}$ oscillations during perception of human and robot actions. Frontiers in neurorobotics, 7(November), 19.

Van Elk, M., van Schie, H. T., \& Bekkering, H. (2010). The N400-concreteness effect reflects the retrieval of semantic information during the preparation of meaningful actions. Biological psychology, 85(1), 134-42.

Villarreal, M., Fridman, E. A., Amengual, A., Falasco, G., Gerscovich, E. R., Ulloa, E. R., \& Leiguarda, R. C. (2008). The neural substrate of gesture recognition. Neuropsychologia, 46(9), 2371-2382.

Virji-Babul, N., Cheung, T., Weeks, D., Kerns, K., \& Shiffrar, M. (2007). Neural activity involved in the perception of human and meaningful object motion. Neuroreport, 18(11), 1125-8.

Wheaton, L. A., \& Hallett, M. (2007). Ideomotor apraxia: A review. Journal of the Neurological Sciences, 260(1), 1-10. 


\section{APPENDICES}

\section{Appendix 1: Complete List of the actions used}

\begin{tabular}{|c|c|}
\hline Object-Related Action (ORA) & $\begin{array}{c}\text { Non-Object-Related Actions } \\
\text { (NORA) }\end{array}$ \\
\hline Putting a hat on & Walking \\
\hline Turning on the light & Running \\
\hline Opening the tap & Jumping \\
\hline Fishing with fishing rod & Hopping \\
\hline Pulling a suitcase & Jumping with legs apart \\
\hline Using a pan & Walking on all fours \\
\hline Color with coloured pencil & Sitting \\
\hline Sawing & Crouching up down \\
\hline Screwing & Kneeling down \\
\hline Drinking from a cup & Climbing on a step \\
\hline Applying toothpaste & Dancing \\
\hline Putting a necklace on & Praying \\
\hline Playing with a ball & Saying hello \\
\hline Drinking from a bowl & Beckoning by waving arms \\
\hline Watering with watering can & \\
\hline \multicolumn{2}{|c|}{ Hammering [a nail] } \\
\hline
\end{tabular}




\section{Appendix 2:}

\section{Normative experiment:}

As briefly presented in the Method section, a normative experiment was used in order to collect a behavioral measure of processing difficulty for each point-lightdisplay (PLD) stimulus. Seventeen participants (who did not take part in the EEG experiment) were submitted to the same familiarization session as in the EEG experiment. One ambidextrous participant was removed from the final analysis. Then, participants performed a meaningful/meaningless discrimination task on the 30 critical Object-Related and Non-Object-Related actions mixed with the 15 transformed meaningless actions. Each action was presented once or twice (counterbalanced between participants) to minimize strategies based on action identity predictability since participants were familiarized with PLD movies beforehand. However, only data obtained from PLD first occurrence were analyzed. The ratio between meaningful and meaningless expected responses was 3/1.

On each trial, the PLD was presented during 1 second and participants had to decide whether the action presented had signification or not. Participants responded by pressing with their finger on two distinct response keys (mapping between response keys and meaningful/meaningless decisions was counterbalanced between participants). Accuracy and reaction times to identify whether the action conveyed meaning or not were assumed to reflect item relative semantic processing difficulty. These measures were used to detect potential outlier items in each condition. The duration of the task was about 4 minutes. 


\section{Figure CAPtions}

Figure 1: Static frame examples of the movies used in the 4 conditions (2 Action Types $\times 2$ Display Types): Object-related actions in normal orientation (in the left upper part of the table: here sawing), its equivalent without signification (left lower part); Non-object-related actions in normal orientation (in the right upper part of the table: Beckoning by waving arms) and its equivalent without signification (right lower part).

Figure 2: Regions of Interest (ROI) defined on basis of the scalp map distribution for each ERP component. Thus, two ROIs were considered for P100, N170 and P3b analyses and only one for P3a and N400.

Figure 3: (a) Event-Related Potentials evoked by the visual presentation of the 4 movie types (2 Action Types [ORA vs NORA] x 2 Display Types [Normal vs Transformed]) under anterior ROI (A1/D1/D2/C1/C2/C11/C12/C21/C22/C23/C24 and $\mathrm{C} 25$ electrodes); (b) Amplitude of P3a components for object and non-object related actions computed on a $60 \mathrm{~ms}$ time window centered on the averaged P3a peak, after subtraction with their corresponding baseline (ORAc, NORAc); (c) sLORETA inverse solution applied to P3a activity (60ms time window centered on the averaged P3a peak) for each movie type. 


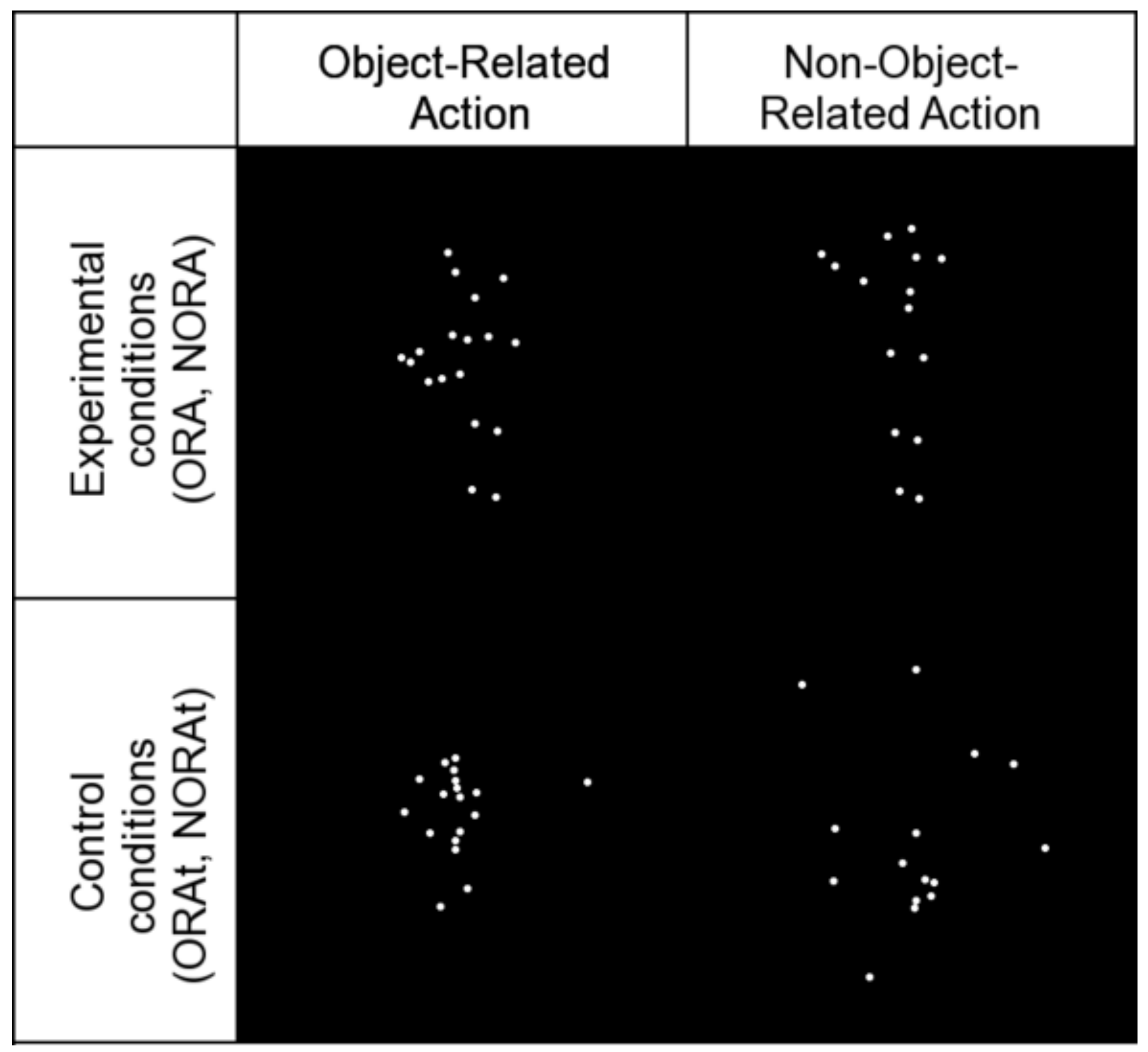

Object-Related Action 


\begin{tabular}{|c|c|c|c|c|c|}
\hline Component & P100 & N170 & P3a & P3b & N400 \\
\hline Latency & $120-150 \mathrm{~ms}$ & $180-220 \mathrm{~ms}$ & $200-300 \mathrm{~ms}$ & $275-400 \mathrm{~ms}$ & $400-600 \mathrm{~ms}$ \\
\hline $\begin{array}{l}\text { Scalp map } \\
\text { distribution }\end{array}$ & & & & & \\
\hline $\begin{array}{l}\text { Electrodes } \\
\text { collapsed } \\
\text { for each ROI }\end{array}$ & $\begin{array}{c}\text { Left: } \\
\text { D31-D32-A10-A11 } \\
\text { A12-A13-A14-A15 } \\
\text { Right: } \\
\text { A26-A27-A28-B7 } \\
\text { B8-B9-B10-B11 }\end{array}$ & $\begin{array}{c}\text { Left: } \\
\text { D30-D31-D32-A9 } \\
\text { A10-A11-A12-A13 } \\
\text { A14-A15-A16 } \\
\text { Right: } \\
\text { A26-A27-A28-A29 } \\
\text { B6-B7-B8-B9-B10 } \\
\text { B11-B12 }\end{array}$ & $\begin{array}{c}\text { Anterior: } \\
\text { A1-D1-D2-C1-C2 } \\
\text { C11-C12-C21-C22 } \\
\text { C23-C24-C25 }\end{array}$ & $\begin{array}{c}\text { Left: } \\
\text { A5-A6-A7-A8-A9 } \\
\text { A10-A15-A16-A17 } \\
\text { A18-D29-D30 } \\
\text { Right: } \\
\text { A28-A29-A30-A31 } \\
\text { A32-B3-B4-B5-B6 } \\
\text { B7-B11-B12 }\end{array}$ & $\begin{array}{c}\text { Anterior: } \\
\text { C2-C4-C8-C9-C10 } \\
\text { C12-C13-C14-C15 } \\
\text { C16-C17-C18-C19 } \\
\text { C20-C21-C25-C26 } \\
\text { C27-C28-C29-C30 } \\
\text { C31-C32-D3-D4 }\end{array}$ \\
\hline
\end{tabular}


(a)

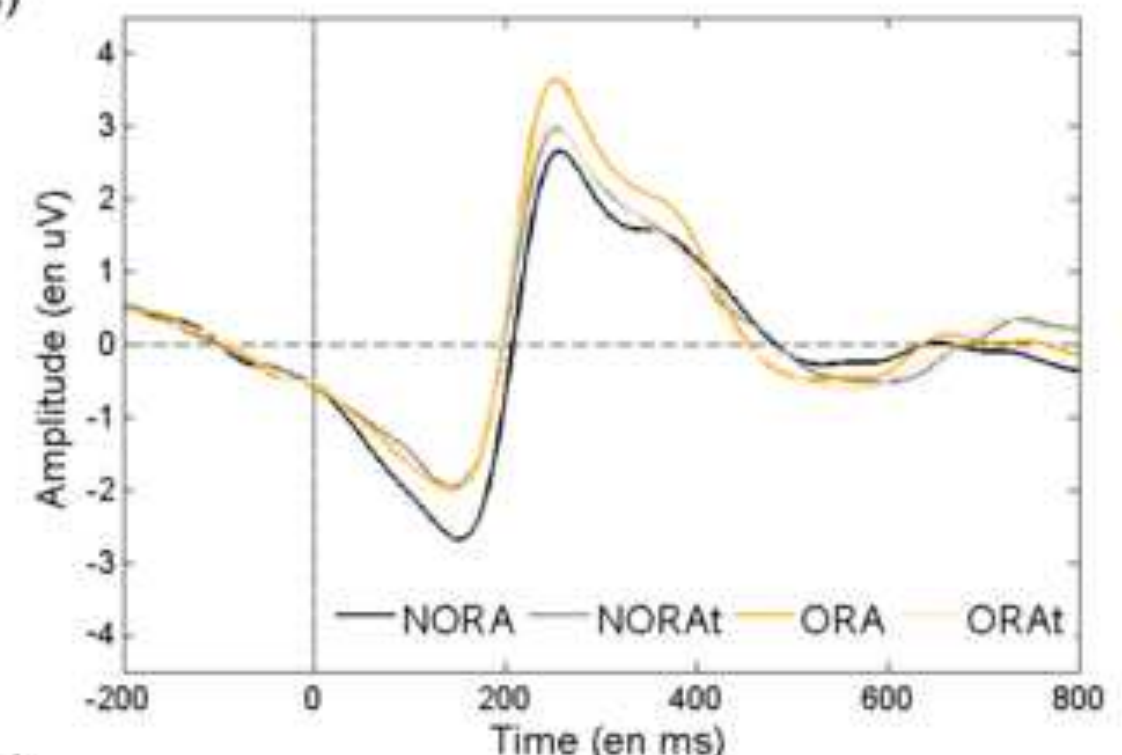

(b)

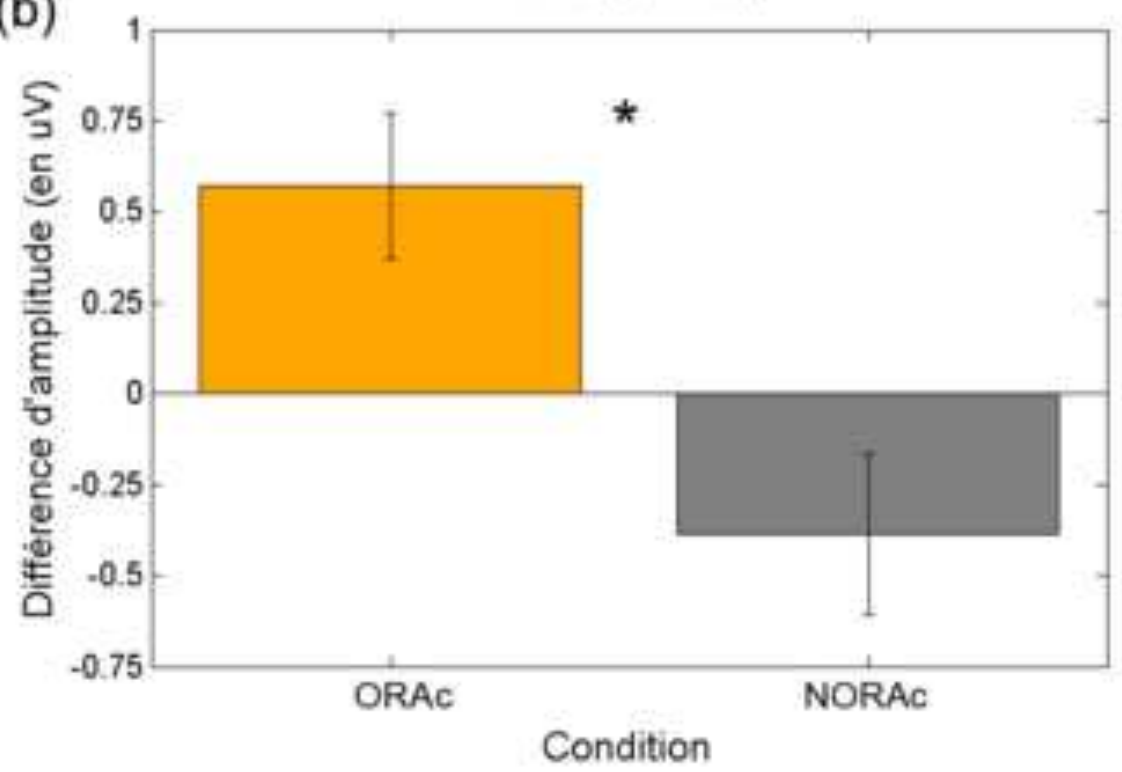

(c)
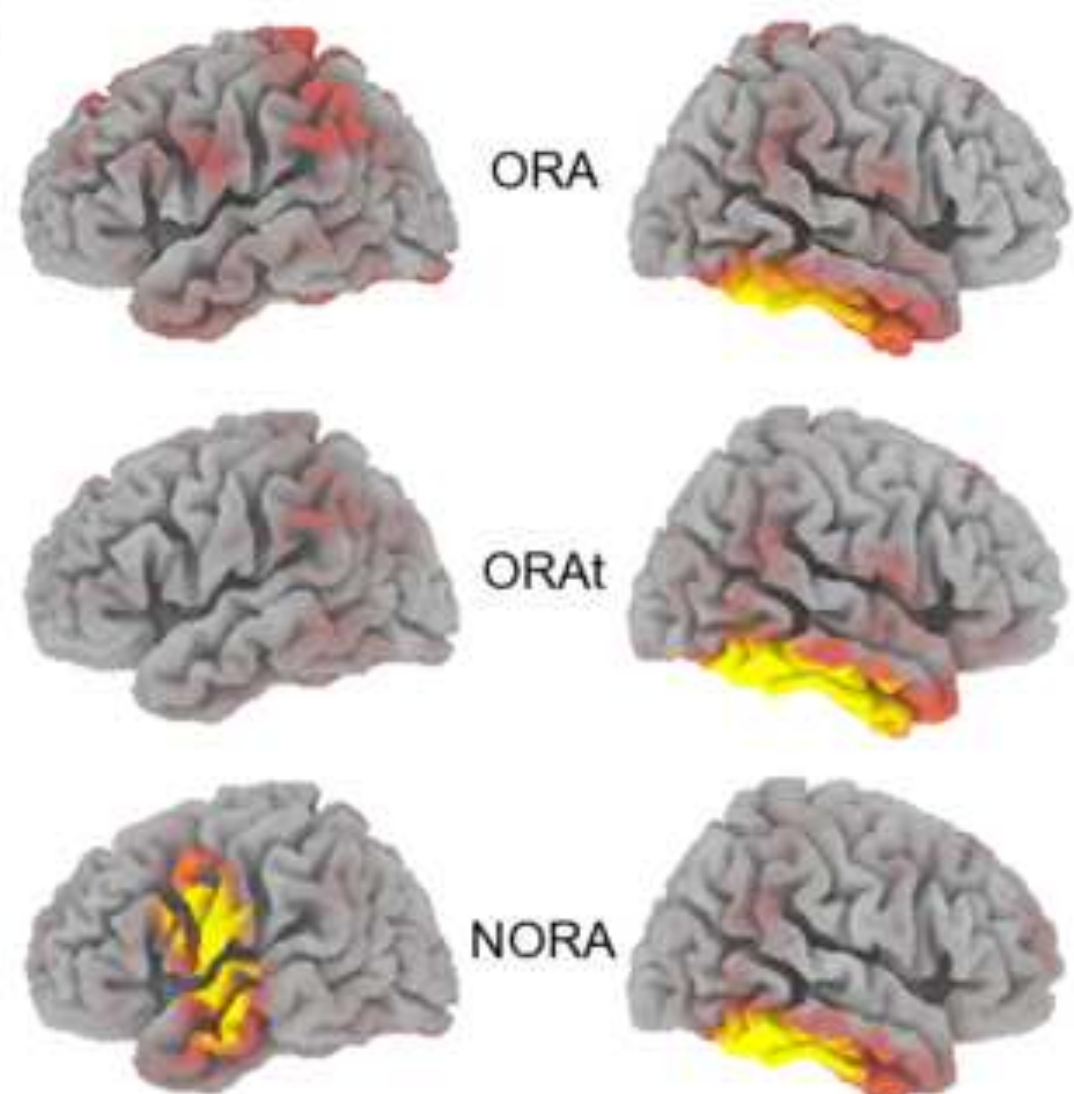

NORA
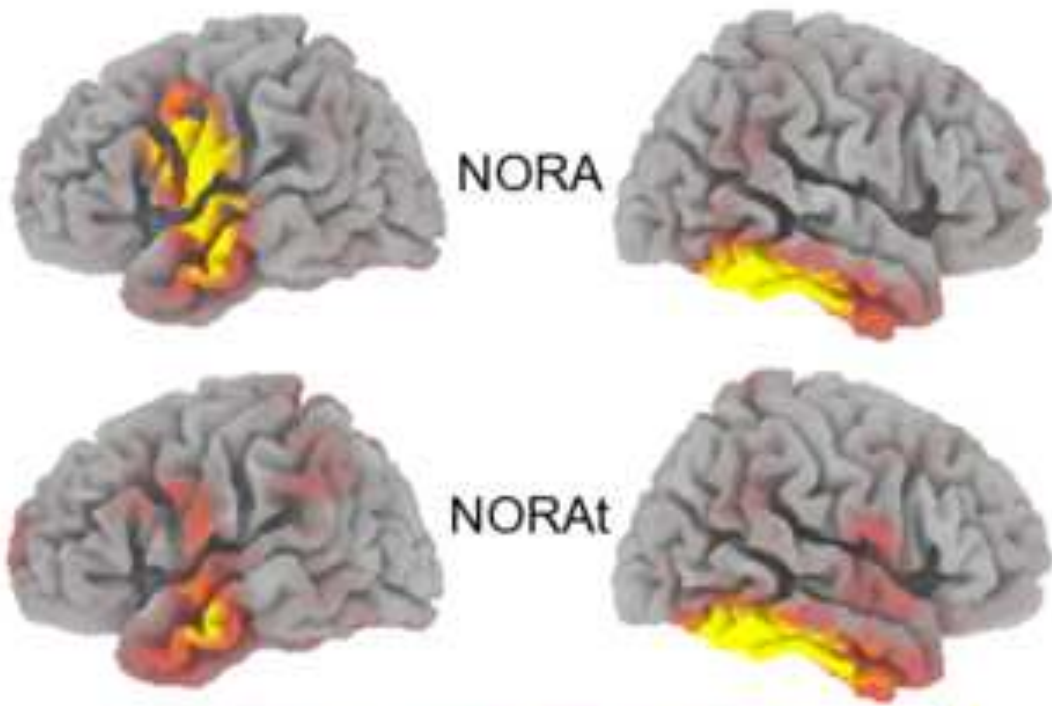

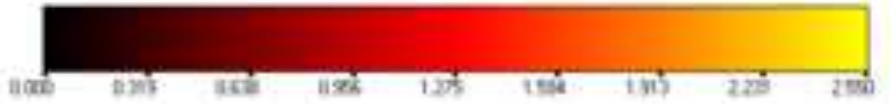

